\title{
Biodiesel and Polyunsaturated Fatty Acid (PUFA) Potential of Microalgae Biomass-A Short Review
}

\author{
Sarpal AS ${ }^{1 *}$, Claudia MLL Teixeira ${ }^{2}$, Paulo RM Silva ${ }^{1}$, Valnei S Cunha ${ }^{1}$ \\ ${ }^{1}$ Instituto Nacional de Metrologia, Brazil \\ ${ }^{2}$ Instituto Nacional de Tecnologia (INT), Brazil
}

ISSN: 2576-8840

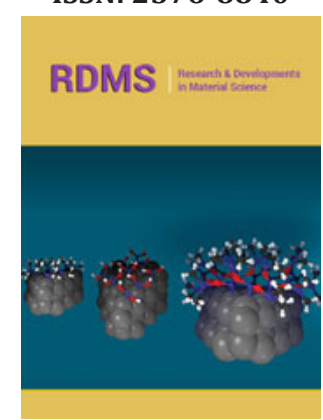

*Corresponding author: Sarpal AS, Instituto Nacional de Metrologia, Qualidade e Tecnologia-INMETRO, Avenida Nossa Senhora das Graças 50, Xerém, Duque de Caxias, RJ, Brazil

Submission: 海 April 03, 2019

Published: 㙁 April 18, 2019

Volume 10 - Issue 4

How to cite this article: Sarpal A, Claudia M T, Paulo R S, Valnei S C. Biodiesel and Polyunsaturated Fatty Acid (PUFA) Potential of Microalgae Biomass-A Short Review. Res Dev Material Sci. 10(4). RDMS.000744.2019.

DOI: 10.31031/RDMS.2019.10.000744

Copyright@ Sarpal AS, This article is distributed under the terms of the Creative Commons Attribution 4.0 International License, which permits unrestricted use and redistribution provided that the original author and source are credited.

\begin{abstract}
A short review is presented on the various aspects of cultivation and characterization of biomasses of microalgae for determination of product potentials, mainly biodiesel and poly unsaturated fatty acids (PUFA). This includes details of product potentials, selection of microalgae species/strains keeping in view of desired product potential, effect of nutrients on the growth and quality of biomass produced, cultivation system (open or closed photo bioreactor), solvent extraction processes for extraction of algal oils, commercial aspects of production of biodiesel, and application of analytical techniques for the component analyses of biomass and algal oils. The applications of FT-NMR, FT-IR and MS/GC-MS techniques have been demonstrated for the analyses of algal oils for product potential of algal oils extracted by ultrasonic method using different solvents. The biomasses of microalgae Scenedesmus sp. and Chlorella sp. were cultivated and harvested on a lab scale. The analytical strategy presented would be useful and cost effective for monitoring the overall cultivation process on a pilot plant or industrial scales including selection of microalgae species and quality of the biomass produced for production of biodiesel.
\end{abstract}

\section{Introduction}

Microalgae (size of micrometers), which is generally found as green suspension on the surface of waste/fresh water, are unicellular photosynthetic organisms that require primarily three components to produce biomass, i.e., water, $\mathrm{CO}_{2}$, and sunlight with relatively higher photosynthetic efficiency of 3-9\% against $0.5 \%$ for terrestrial plants. The microalgae grow in aquatic environment in diverse sources of water such as fresh, industrial waste, marine, brackish and open ponds or lakes. Microalgae grow best in waste water by utilizing the essential nutrients $\mathrm{N}, \mathrm{P}$ and $\mathrm{K}$ of the industrial effluent required for the cultivation and growth of microalgae. Microalgae needs less water (20L of water/L of oil) compared to regular terrestrial crops (3000L of water/L of oil). Microalgae can either be autotrophic or heterotrophic under natural growth conditions [1-3]. Algal lipids have 20-50\% oil content which is higher than soybeans oil $(18 \%)$ and palm oil $(40 \%)$. However, the productivity of biodiesel (liter/hectare/year) is much higher $(\sim 100000)$ for microalgae compared to soybean oil (661) and palm oil (5585). These are following major advantages of cultivation of algae over regular vegetable crops that attract attention of cultivators [3-8]:

1. High growth rate (200 times or more than conventional vegetable crops (liter/ hectare/year).

2. Accumulate higher amounts of lipids up to $60 \%$ compared to conventional crops up to $5-7 \%$ of DW.

3. Biodiesel yield 5000-20000 gallon/acre/year compared to 50-500 gallon/acre/year for crops.

4. Microalgae can grow in non-arable land, seawater or brackish and waste industrial water with higher photosynthetic efficiency (average 3-9\% sun light irradiance) and $\mathrm{CO}_{2}$ sequestration capacity. No competition for resources with classical agriculture sources.

5. The composition of the biomass (lipids, carbohydrates or protein, neutraceuticals accumulation) can be monitored by varying the cultivation and growth parameters such as nutrients, light efficiency etc. 
6. Continuous production during the whole year will be possible employing effective process engineering tools for photo bioreactor, inoculation, light penetration and harvesting.

7. Renewable oil, higher biodiesel and food potentials.

8. It can be digested to produced biocrude and methane.

9. It is a rich source of nano-materials (frustules) for advanced devices.

Microalgae cultivation process is environment friendly, mitigate $\mathrm{CO}_{2}$ and NOx from industrial flue gases by biofixation besides active agent of industrial wastewater bioremediation by removal of hazardous pollutants including heavy metals and dyes [7]. In addition, algae biodiesel contains no sulfur and performs as well as petroleum-based diesel, while reducing emissions of particulate matter (PM), CO, hydrocarbons, and $\mathrm{SO}_{\mathrm{x}}[3,4,6]$. The oil rich microalgae species of higher biomass productivity (20200mg L-1day-1) are Nannochloropsis, Botryococcus, Scenedesmus, Spirulina, Chlorella, Dunaliella, Phaeodactylum tricornutum, Isochrysis galbana, Monodus subterraneus, Tetraselmis and C. reinhardtii, which are extensively cultivated because of their biodiesel and food potentials [1-10], The microalgae Isochrysis, Phaeodactylum tricornutum, Pavlova, Thalassiosiracan, Chlorella and Scenedesmus species under controlled environement cultivate sufficient amount of omega-3 poly unsaturated fatty acids (PUFAs) which can be used as an alternative for fish oil [[8-12] and references there in]. The most important motivating factor of growing microalgae is due to its lipids content of 2-80 percent of total dry cell matter depending on the types of species and growth conditions employed for cultivation [2-4].

The lipids of microalgae biomasses are comprised of neutral lipids (storage), polar lipids (structural), carbohydrates, hydrocarbons, and valuable co-products. Over 15,000 novel compounds originate from algae biomass. The neutral lipids, triacyl glycerides (TAG) and free fatty acids (FFA), present in microalgae dry biomass, are the main potential components of interest to the biodiesel industry. Like oilseed crops such as rapeseed and soybean oil, which have been extensively evaluated as sources of biodiesel, biodiesel from microalgae are regarded as a promising alternative environmentally sustainable renewable source of fuel for IC engines [8-10,13-16]. Chemically, biodiesel is a mixture of fatty acid mono alkyl esters. It is produced by a transesterification reaction between natural occurring triglycerides and alcohol in the presence of a catalyst $[17,18]$. The fatty acid content and composition comprising of algae lipids are entirely dependent upon the types of species and cultivation conditions, mainly nutrients, employed for their cultivation [1-3,5,8]. Other potential utilization of microalgae is production of biofuels such as bio-hydrogen, renewable diesel and jet fuel (deoxegenation, hydrotreating), bio-ethanol and bio-butanol $[1,18,19]$. Besides neutral lipids and polar lipids, various high-value co-products such as epoxy esters, pigments, antioxidants, $\beta$-carotenes, polysaccharides and vitamins can be extracted from microalgae. These co-products find extensive applications in pharmaceuticals, cosmetics, nutraceuticals, and functional foods industries $[16,20]$.
The oleaginous Microalgae biomass, consider as green gold of future, is enriched with neutral lipids, triacyl glycerides (TG). Biodiesel potential of oleaginous microalgae biomass is associated with the biomass productivity, mainly content and quality of neutral lipids, achieved during cultivation process. The fatty acids profile of algal oil is comprised of C12-C24 saturated and unsaturated fatty acids, which is more or less similar to those present in vegetable and fish oils [8-10]. TGs from microalgae biomass are converted into fatty acid methyl ester (FAME) (biodiesel) by usual chemical hydrolysis followed by esterification or enzymatic transesterification $[17,18]$. Biodiesel from microalgae can be used as B100 (neat biodiesel) or blended with conventional diesel at a level of $5 \%$ (B5) or $7 \%$ (B10) or 20\% (B20) [18-21]. Most of microalgae biomasses are rich sources of n-3 $\omega 3$ and n-6 $\omega 6$ fatty acids including C18:3, C20:5 (Eicosapentaenoic acid, EPA) and C22:6 (Docosahexaenoic acid, DHA) as indicated by very high iodine value of 90 to 140 of solvent extracts $[8,11,12,20]$. Thus, biodiesel from algal oil is not an appropriate fuel for direct combustion in sensitive engines due to its high content of PUFAs. However, extraction of PUFA by solvent extraction methods or hydrotreating/hydrocracking of algal oil are considered useful options for making biodiesel with oxidation stability similar to those inherited by biodiesel from oil crops (ASTM D6751) [21-24].

Dunaliella salina, Parva and Teriolecta, sp. and Tetraselmis are specific sources of carotenoids including $\beta$-carotene, vitatamin A, axtaxanthin. violaxanthin (Vio), diadinox anthin (Ddx) and diatoxanthin (Dtx), which find extensive application as natural source of food supplements with several proven health benefits to human being $[16,25]$. These species have also been found to contain neutral lipids (tri-glycerides), which can be used for both biodiesel and food products. The diatom microalgae species are capable of fabricating silica frustules (inner walls) with morphologies diversity in shapes \& structures and hierarchical architectures, ranging from nanometers to micrometers. Frustule structure could be used in building advanced devices such as light harvesting, photonics, molecular separation, sensing, and drug delivery systems. Because of the light sensing unique architectures of the frustules, these are also potential materials for optical, mechanical and transport devices with enhanced desirable properties [26].

Algae are also able to accumulate highly toxic substances such as selenium, zinc and arsenic in their cells and bodies thus eliminating such substances from aquatic environments. Radiation is also an important type of pollution as water bodies contains naturally radioactive materials or become radioactive through contamination. The ability of algae to accumulate metals and reduce metal ions makes them the superior contender for the biosynthesis of nanoparticles (NPs). Nanoparticles such as silver (Ag), iron oxide $\left(\mathrm{Fe}_{3} \mathrm{O}_{4}\right)$, titanium oxide $\left(\mathrm{TiO}_{2}\right)$, copper oxide $(\mathrm{CuO})$, zinc oxide $(\mathrm{ZnO})$ and gold $(\mathrm{Au})$ are certain examples of inorganic NPs. These are potent antibacterial agents being synthesized using aqueous extract of microalgae employing aqueous phytochemicals-based synthesis by species such as Chlorella vulgaris, Diatom Chaetoceros Calcitrans and Cyanophyta, Nannochloropsis Oculata, and Spirulina Platensis as reducing agents, and size of NPs synthesized ranged between 15 and $47 \mathrm{~nm}$ [27]. 
Effect of cultivation parameters on productivity and quality aspects of biomass

The following sections discuss the overall cultivation process for the production and analyses of biomass obtained from various microalgae species:

Effect of nutrient and light intensity: Commercial including cost and economic aspects of cultivation of microalgae are that biochemical composition of the algal biomass can be altered by selection of proper species/strains and varying cultivation parameters. This can significantly enhance the biomass productivity and oil yield, effect the chemical composition and fatty acid profile, and improve their quality aspects, and also provide viable options either in favor of biodiesel or value-added products. The composition and nature of neutral lipids and their fatty acids profile including PUFAs, are dependent on the cultivation parameters such as temperature, composition of nutrients $\left(\mathrm{NaCl}, \mathrm{KCl}, \mathrm{MgSO}_{4} 7 \mathrm{H}_{2} \mathrm{O}\right.$, $\mathrm{CaCl}_{2}, \mathrm{NaHCO}_{3}, \mathrm{NaNO}_{3}$, Urea, $\mathrm{NaH}_{2} \mathrm{PO}_{4}, \mathrm{CUSO}_{4}, \mathrm{COCl}_{2}$ etc.), types of feed, light intensity etc. [1-5,8-10]. The different lipid induction techniques such as environment stress, nitrogen limitation or starvation, salinity factor, light irradiation, genetic modification etc. have been used to enhance the biomass and lipid productivity. Relatively high biomass production cost and low lipid productivity combined with low lipid extraction efficiency have been recognized as major obstacles impeding commercial production of biodiesel from microalgae. Lipid production is modulated by variation of culturing parameters such as nitrogen and phosphate concentration and their source, light source and density of photonic flux, metal content and salinity in order to enhance lipid productivity with desired fatty acids profile [[8,9] and references therein]. Altering the biosynthesis pathways through genetic modification has also been adopted as means for lipid yield and quality improvement $[1,3]$. The occurrence and the extent to which TGs are produced is species/strain specific and are ultimately controlled by the genetic make-up of individual organism. Under environment stress or lipid induction techniques, the TG content can be increased to 20 to $50 \%$ of the dry cell weight [1-4].

Microalgae demonstrate optimum growth efficiencies at illumination intensities of about $100 \mu \mathrm{E} /(\mathrm{m} 2 \mathrm{~s})$ compared to values up to $2000 \mu \mathrm{E} /(\mathrm{m} 2 \mathrm{~s})$ on a sunny tropical day. The effect of UV irradiance for lipid induction has been shown to affect the fatty acid profile, particularly PUFAs with DHA and EPA chain. The N and P limitation has been used to control the production of PUFA, particularly change in the stereochemistry and regioisomerism ie positional isomers containing PUFA and other saturated fatty acids. Regioisomeric characterization of triacylglycerols containing palmitic, arachidonic (ARA) and eicosapentaenoic acids (EPA) showed that the proportion of positional isomers was affected by N- and P-starvation $[8,9,28,29]$.

\section{Selection of microalgae species}

Strain selection can be performed with a special focus not only on generally applied selection criteria, such as lipid content and lipid productivity, but also on the fatty acid profiles matching biodiesel requirements (ASTM D6751). The higher saturated fatty acid/ester containing biomass is useful in view of oxidation stability and higher cetane requirements. Further selection criteria for microalgae need to be considered as they mainly influence the ability to produce biomass at a large scale in the respective environments. The essential parameters for commercial production with higher bio and lipid productivity such as strain-specific optimal temperature range, salinity of the cultivation medium, and the ability to maintain for longer periods in nonaxenic cultures must be considered. Botryococcus braunii (25-75\%), Schiochytrium (52-75\%), Nanochloris \& Nanochloropsis (20-68\%), Chlorella vulgaris (28-32\%), Tetraselmis sueica (15-23\%) and Dunaliella primolecta $(\sim 23 \%)$ are some of the high oil yielding species $[1,2,6]$. Besides species or strain specific, lipid bio productivity, growth rate, its quality aspects such as types of fatty acids (saturated or unsaturated), and types of photo bioreactor or inhibiting conditions are important factors that should also be considered for lab and on large scale production [30-33].

\section{Cultivation system}

The biomass productivity depends upon the cultivation system, open or closed photo bioreactors. Traditionally, microalgae are cultivated in the so-called open ponds for mass production, which are natural or artificial bodies of standing water typically 20 to $30 \mathrm{~cm}$ deep. The photo conversion efficiency (PCE) of microalgae cultivation is $3-9 \%$ compared to about $0.5 \%$ of agriculture crops. It is increased to some extent by use of open pond raceways system with paddle wheel, which is cost effective and used for mass cultivation of algae biomass. This is mainly because raceways are poorly mixed and optimum light intensity cannot be achieved. Also, open facilities exhibit high water evaporation per ground area $\left(1\right.$ to $\left.3 \mathrm{~m}^{3} \cdot \mathrm{m}^{-2}\right)$ and pose a high risk of contamination. In order to achieve increase productivity, better mixing is required for improved gas transfer and exposing more cells to the light on the surface. Closed photo bioreactor with different shapes and design such as tubular, helical, flat panel, horizontal and vertical, are most efficient photosynthetic mass cultivation system with biomass productivity achieved up to $0.215 \mathrm{~g} \mathrm{~L}^{-1} \mathrm{~d}^{-1}$. This is because high algal biomass concentrations can be achieved in closed PBR systems due to increase surface areas, sufficient sunlight penetration capability and control of energy saving as well as least chances of interferences by environment. It is also convenient to maintain monoculture system in case of closed photo bioreactor system in contrast to open pond system. In case of bioreactor, the culture volume is separated from the environment by transparent walls leading to less evaporation, less contact interface for possible invasion by competing microalgae, contaminating bacteria, or multi cellular grassers. High oil species of microalgae cultured in growth-optimized conditions of photo bioreactors have the potential to yield 19,000-57,000 liter of micro algal oil per acre per year. The other effective and economical cultivation systems are water stabilization ponds and advanced integrated waste water pond algal high rate ponds. An ideal biomass productions system should use the freely available sunlight with high penetration light mechanism as the preferred and most economic source of light used for the cultivation of microalgae [1-5, 8,31-33]. 


\section{Extraction of lipids from algae biomass}

In order to produce biodiesel by usual process of transesterification, lipids and fatty acids are extracted from the microalgae biomass. Since algal biomass contain many cells joined together by tough cellulose walls, the efficacy of mechanical cell disruption and breakage of the filaments and subsequent extraction are dependent on the polarity of solvent used for extraction of oil, the lipids constituting fats and co-products. Lipids extraction efficiency is directly related to the overall process efficiency and considered important step in determining the overall cost of production of biodiesel. Chemical solvent extraction methods in combination with milling (expression, expeller and bead milling/beating) are applied to extract neutral lipids. Chemical methods involve extraction by solvents such as hexane/cyclohexane, chloroform, methanol, isopropanol and their mixtures by use of Soxhlet, Accelerated Solvent Extraction (ASE), Sonication and Supercritical Fluid Extraction (SFE) methods [1,2,8-10,34]. Soxhlet extraction process using hexane and milling in combination with hexane are quite efficient in the extraction of neutral lipids (TG, FFA), which are easily esterified into biodiesel $[8,17,18,22]$. Ultrasonication and microwave assisted extraction with appropriate solvents have many advantages such as reduced extraction time, reduced solvent consumption, and greater penetration of solvent into cellular materials causing high cell disruptive effects for quick release of oils. Extractions using the subcritical or supercritical fluids (ethanol), mainly supercritical $\mathrm{CO}_{2}$, are applied to extract lipids and considered economically viable and green process as drying process is completely eliminated [24,25,35-37].

\section{Analytical strategy for biodiesel and PUFA potential of algae biomass}

Analytical techniques such as chromatographic and mass spectrometry (GC, MS, GC-MS, HPLC, GPC), IR and Raman Spectroscopy, NMR Spectroscopy, Flourescence and Atomic spectrometry (XRD, SEM, TEM) are being used extensively for lipid content and compositional analyses including fatty acid profile, monitoring the production, quality of feed stocks and conversion to biodiesel. The determination of lipid content in algae biomass is carried out by the methods based on solvent extraction followed by gravimetric lipid quantification, and based on analytical techniques, fat cellular staining by fluorescence microscopy using a lipid stain such as Nile Red, solid state time domain Nuclear Magnetic Resonance (TD NMR) for direct estimation, liquid state NMR, FTIR by statistical correlation and FAME conversion by GCMS. Specifically, high-pressure liquid chromatography (HPLC) and NMR methods can be used to quantify different types of lipids in algal extracts e.g., mono, di, and triglycerides. Gas chromatography alone and coupled with mass spectrometry (GC-MS) is used routinely to identify and quantify fatty acid methyl esters from algal and yeast extracts [8-10,13-17,38 and references therein]. Total oil content including neutral and polar lipids determination is generally carried out by estimation by Soxhlet (AOAC, 1980) or by cold extraction methods using organic solvents, and the fatty acid composition of the extracted oil is determined by gas liquid chromatography after trans-methylation. Oil extraction followed by esterification is cumbersome, time consuming, and often uneconomical. Therefore, analytical methods are preferred as both total oil content and compositional information are obtained [8-10,38-42].

\section{NMR spectroscopic techniques}

High-resolution Nuclear Magnetic Resonance (NMR; 1H, 13C) spectroscopic techniques (1D \& 2D) due to their inherent sensitivity, high resolution and multinuclear capability offer many advantages over existing analytical methods due to ease of direct, rapid, simultaneous and nondestructive analyses in the multicomponents system of fats, algal oils, and biodiesel obtained from different sources [8-10,13-17]. The diverse format of applications include detailed quantitative compositional analyses such as lipid/fat content, PUFA content, fatty acid profile (saturated and unsaturated), iodine value etc. and industrial aspects such as production and quality monitoring of seeds, oil and biodiesel from different sources [8-10]. NMR $(1 \mathrm{H}, 13 \mathrm{C})$ techniques have been proved to be authentic, rapid, precise and quantitative, and provide direct quantitative analyses without the use of standards. Single component standards such as triglyceride oleate, stearate or palmitate have been used for comparing the fatty acid profile, saturated or unsaturated, of the algal oils. The matrix effect has not been taken care of while using the single component standards for quantitative analyses of lipid content in the algal extracts $[8,43]$. Without considering effects of matrix, results may be misleading due to overlapping chemical shift regions or resemblance with the matching structures in the complex matrices containing multi component system of TG, FFA and polar lipids. The Fatty acid composition profiles by NMR methods are direct and simple and quite comparable to those determined by GC-MS methods $[8,41,42]$.

The accurate determination of neutral lipids in the algae biomass is a challenging task due to presence of complex multi component matrix comprising of glycerides, glycerolglyco/phospho lipids, proteins, carbohydrates and minor constituents [8,38,41,42]. Thus, there is an essential requirement for standardization of methods in order to ensure reproducibility and accurate assessment of lipid yield and productivity of produced biomass [43]. The applications of $1 \mathrm{H} \& 13 \mathrm{C}$ NMR (1D,2D) techniques have been demonstrated for the determination of quality parameters of algal oils and their corresponding biodiesel derived from different microalgae species (Chlorella vulgaris, Scendesmus ecornis/oblique, Tetraselmis chuii, Spirulina and Dunaliela) cultivated in the diverse nutrient composition and cultivation parameters as reported by us previously [8-10,13-17,42].

\section{Demonstration of NMR, FTIR and GC-MS techniques for monitoring the composition of algal oils}

NMR: In order to apprise the readers of the methodologies involved in the determination of important quality parameters of algal oils, that will determine the ultimate quality of the final product biodiesel (ASTM D6751), the 1H NMR spectra of two solvent extracts (algal oils), namely Chlorella vulgaris and Scenedesmus ecornis microalgae species belonging to family Chlorellaceae, cultivated on 
a lab scales in the WCSPS (WC, superphosphates, Chelean salt peter) nutrient medium are shown in the Figure 1. Both these species are extensively cultivated for biomass for biodiesel and food products due to their relatively fast growth compared with other microalgae species, and economic suitability for outdoor large-scale cultivation $[8,9]$. The spectral features of the various functional groups of the triglycerides (fats) comprised of different fatty acids in the algal oils are compared with those of soybean and fish oils as depicted in the same Figure 1.The chemical shift regions characteristic of functional groups of glycerides back bone comprised of saturated (C14: 0, C16:0, C18:0) and unsaturated (C18:1, C18:2, C18:3, C20.5, C22:6) fatty acids chain are marked in the Figure 1 for complete understanding of structural features of neutral and polar lipids of algal oils. The quality parameters including fatty acid profiles are determined by derivation of the following equations based on NMR integral intensities of characteristic functional groups as marked in the Figure 1 as described previously [8,10,42]:

$\mathrm{TG}=26.06 \times 2 \varkappa \mathrm{ITG}-0.62(4.25-4.34 \mathrm{ppm})$ Eq 1 [8]

FFA=23.57xIFFA -7.84 (2.32-2.38ppm) $\quad$ Eq 2 [8]

$$
\begin{array}{cc}
\text { BD (biodiesel })=12.33 \varkappa \text { IOCH3 }(3.67 \mathrm{ppm}) & \text { Eq } 3[10,42] \\
\text { PUFA=10.75xIPF }(0.925-1.02 \mathrm{ppm}) & \text { Eq } 4[10,42] \\
\text { C18:3 }(\alpha \text { or } \gamma)=10.75 \mathrm{xILA} & \text { Eq } 5[10,42] \\
\text { UFA=8.52xIUFA + 4.14(0.925-1.02ppm) } & \text { Eq } 6[10,42] \\
\text { DHA(C22:6)=16.33xIDHA }(2.38-2.42 \mathrm{ppm}) & \text { Eq } 7[10,42] \\
\text { Iodine value (IV)=15.78xIV }(5.05-5.65 \mathrm{ppm}) & \text { Eq } 8[14]
\end{array}
$$

Where ITG, IFFA, IV etc. are the integral intensities of the chemical shift regions of the functional groups corresponding to triglycerides (TG), free fatty acids, unsaturation etc. as marked in the Figure 1, and Figures given in the respective references.

As described in the preceding sections the algal oils are transesterified in order to convert into FAMEs i.e. biodiesel and 1H NMR spectral technique could be used to monitor the process as well as determination of fatty acid profile $[8,9,41,42]$. This has been demonstrated in the Figure 2 in case of algal oil of Chlorella vulgaris.

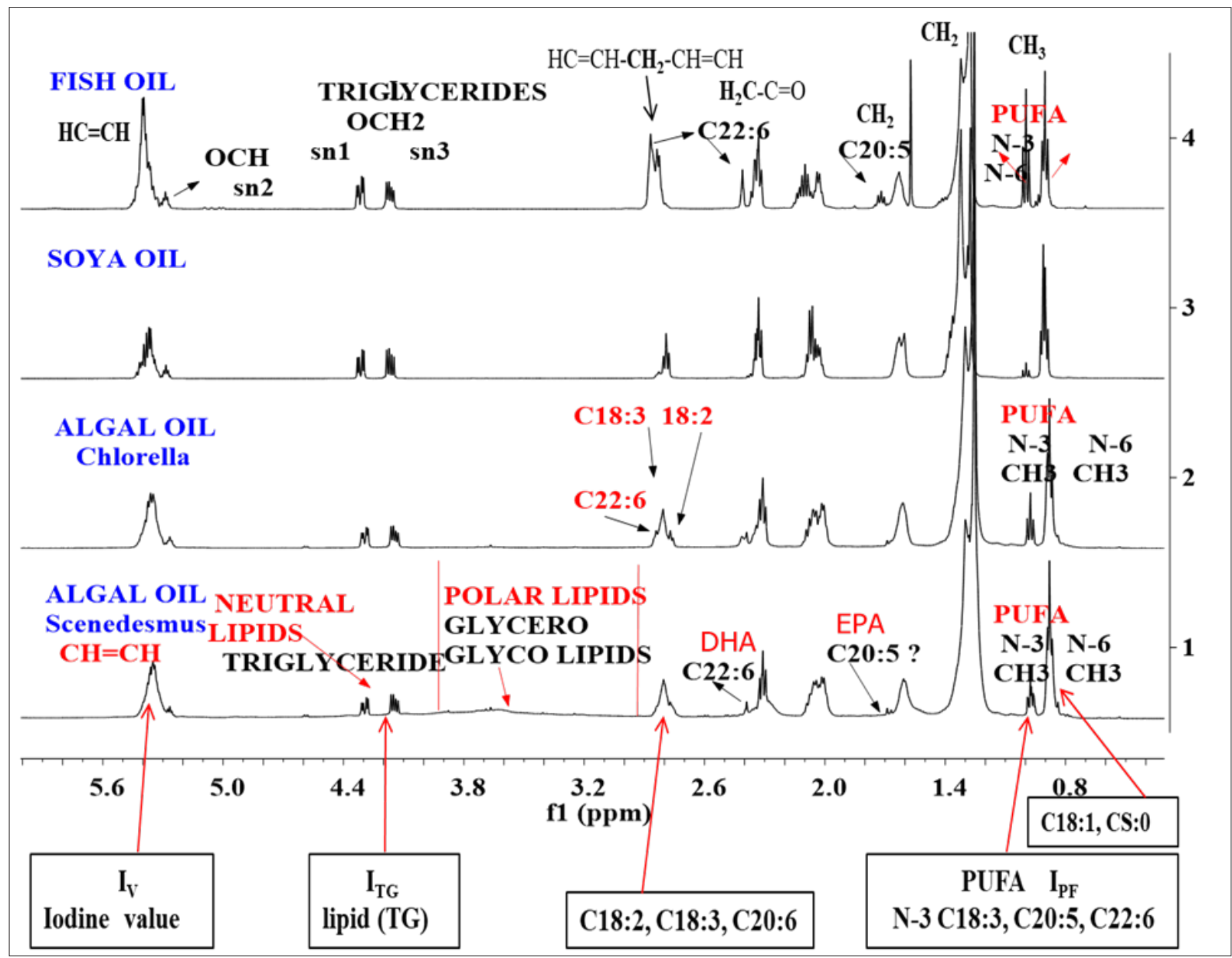

Figure 1: $500 \mathrm{MH}$ 1H NMR spectra of cyclohexane extracts (algal oils) of micro algae biomasses Scenedesmus ecornis \& Chlorella vulgaris cultivated in WC-Superphoshate-Chilean saltpeter medium, soybean oil and fish oil marked with characteristic functional groups of lipids (neutral and polar) and fatty acids constituting these lipids. Iv, ITG etc. are the integration values of the respective region of functional groups for determination of these quality parameters. 


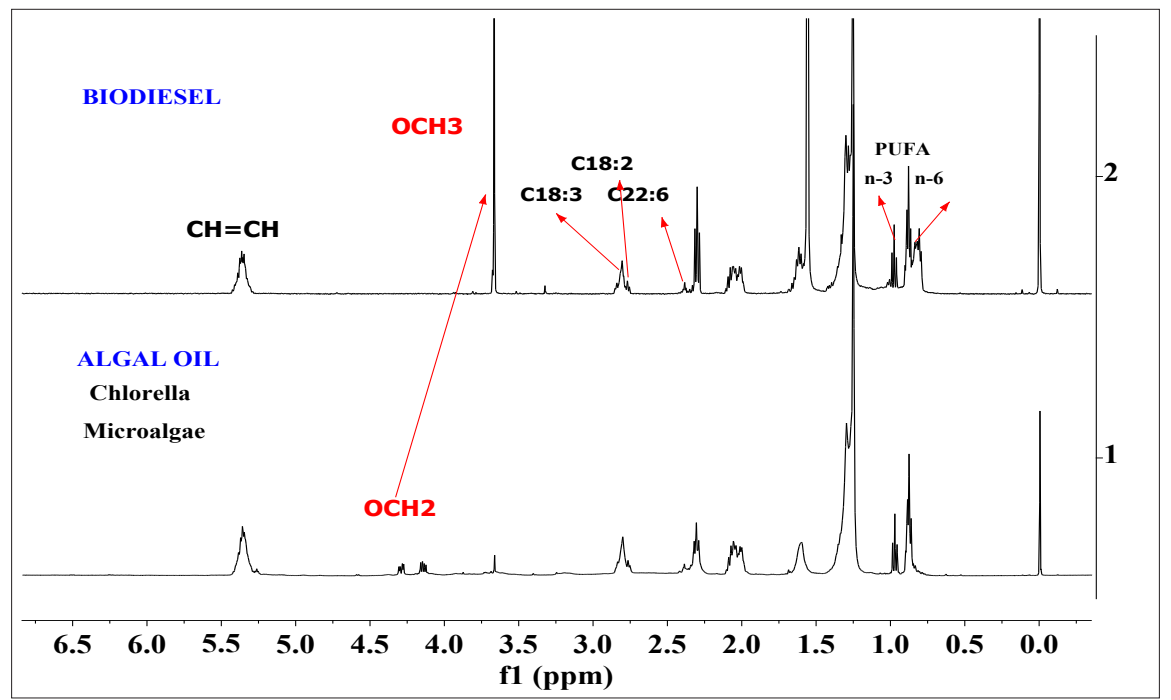

Figure 2: $500 \mathrm{MHz} 1 \mathrm{H}$ NMR spectra of biodiesel obtained from transesterification of corresponding algal oil (chloroform-methanol extracts) cultivated in WC-Superphosphate-Chilean saltpeter medium, marked with chemical shift regions of characteristic functional groups.

\section{Fatty acid profile determination by GC-MS}

MS and GC-MS (EI, MALDI-TOF, ESI, Ion mobility) techniques are well suited for the determination of fatty acid profile of TG of algal oil directly and FAMEs of algal oils as explained systematically in numerous publications [8,9,42-48]. Direct analyses of algal oils of biomasses obtained under diverse cultivation and harvesting stages by NMR and MS techniques are useful for determination of fatty acid profile of intact tri glycerides (TG) in order to assess the PUFA potential and quality of biodiesel. The MS and 13CNMR techniques conveniently provide regioisomerism/positional i.e. distribution of fatty acid at the sn1, sn2 and sn3 position of acyl chain of glycerides. This is particularly useful for distribution of PUFAs (C18:3, C20:5, C22:6) in these position for assessment of quality of infant food products being manufactured from PUFAs of algal oils [49]. The Positional distribution of fatty acids in the neutral (tri-glycerides) (TG) and polar lipids (glycerol/glyco/phospho) of algal oil (cyclohexane extract) of Scenedesmus ecornis sp. by ESI-MS technique are shown in the Figure 3. It is further understood that there are only few molecules of TGs comprising of only homo nature of fatty acids such as 000 or LLL or LnLnNn. Similarly, the fatty acid profile of FAMEs of algal extracts of Scenedesmus ecornis sp. and Chlorella vulgaris determined by GC-MS (quadrupole) are shown in the Figure 4 for the purpose of comparative analyses of fatty acids. It is evident from the profile that both saturated and unsaturated fatty acids are present in the neutral and polar lipids. The C22:6, C20:4 and C18:3 are part of both the algal oils besides the presence of usual saturated and unsaturated fatty acids. The Table 1 shows the fatty acid composition of four algal oils obtained from different microalgae species in comparison to soybean and fish oils.

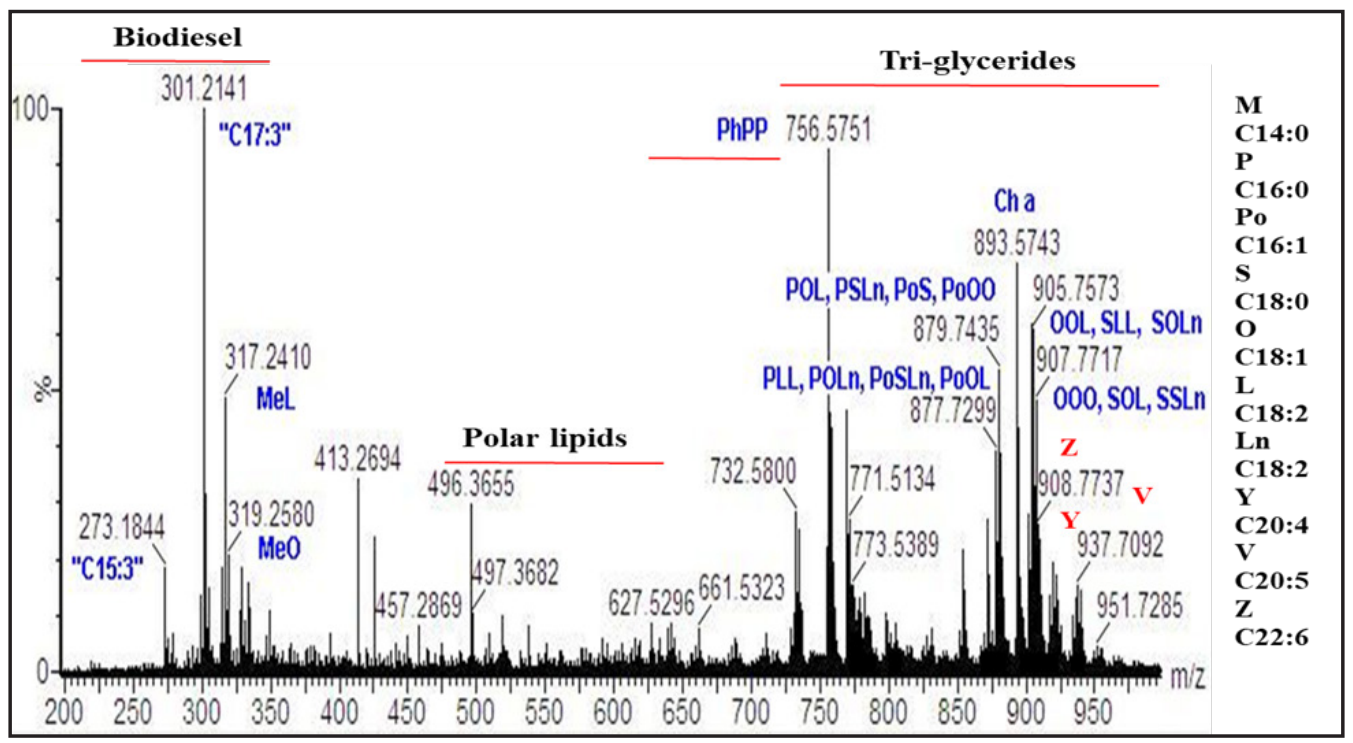

Figure 3: ESI-MS profile of Scenedesmus ecornis algal oil containing triglycerides, polar lipids (Glycero/glycol) and FAMEs (biodiesel). Ph=Phospho lipids, Me=Methyl 
Table 1: Fatty acid profiles of FAMEs of algal oils, soybean oil and fish oil determined by GC-MS.

\begin{tabular}{|c|c|c|c|c|c|c|}
\hline Carbon No. & $\begin{array}{l}\text { Algal Oil } \\
\text { SNDA }\end{array}$ & $\begin{array}{l}\text { Algal Oil B } \\
\text { SNDB }\end{array}$ & Algal Oil CHLEFWC & Algal Oil CHLEF & Soybean & Fish Oil \\
\hline C14:0 & 0.8 & nd & nd & nd & nd & 7.3 \\
\hline C16:0 & 23.4 & 20.6 & 39.5 & 24.2 & 14.1 & 17.9 \\
\hline C16:1 & 1.9 & 1.1 & 3.5 & 0.2 & nd & 10.4 \\
\hline C16:2 & 1.5 & 1.1 & 0.3 & 1.5 & nd & 1.3 \\
\hline C16:3 & 3.3 & 4.9 & 1.5 & nd & nd & 1.4 \\
\hline C17:0 & 7 & 0.8 & nd & nd & nd & nd \\
\hline $\mathrm{C} 17: 1$ & nd & 5.2 & nd & nd & nd & nd \\
\hline C18:0 & 3.1 & 3.3 & 1.5 & 2.3 & 5 & 3.9 \\
\hline C18:1 & 25.6 & 32.2 & 21.4 & 33.6 & 24.1 & 18.8 \\
\hline C18:2 & 6 & 10.3 & 11.2 & 13.8 & 49.3 & nd \\
\hline C18:3(n-3) & 16.9 & 12.3 & 14 & 16.4 & 7.1 & nd \\
\hline C18:3(n-6 & 2.6 & nd & nd & 0.1 & nd & nd \\
\hline C20:4 & nd & nd & 1.3 & 2.1 & nd & 1 \\
\hline $\mathrm{C} 20: 5$ & nd & nd & nd & nd & nd & 19.2 \\
\hline $\mathrm{C} 22: 6$ & $\mathrm{p}$ & $\mathrm{p}$ & $6.0^{*}$ & $5.8^{*}$ & nd & 12.3 \\
\hline UI & 7.9 & 8.2 & nd & nd & 0.6 & 6.5 \\
\hline
\end{tabular}

nd=not detectable or present, $\mathrm{p}=$ included in UI (unidentified), * by NMR (GC detected but could not be quantified); SNDA=Scenedesmus strain1, SNDB=Scenedesmus strain 2, CHLEFWC (Chlorella cultivated with effluent water and WC medium), CHLEF (Chlorella cultivated with only effluent water)

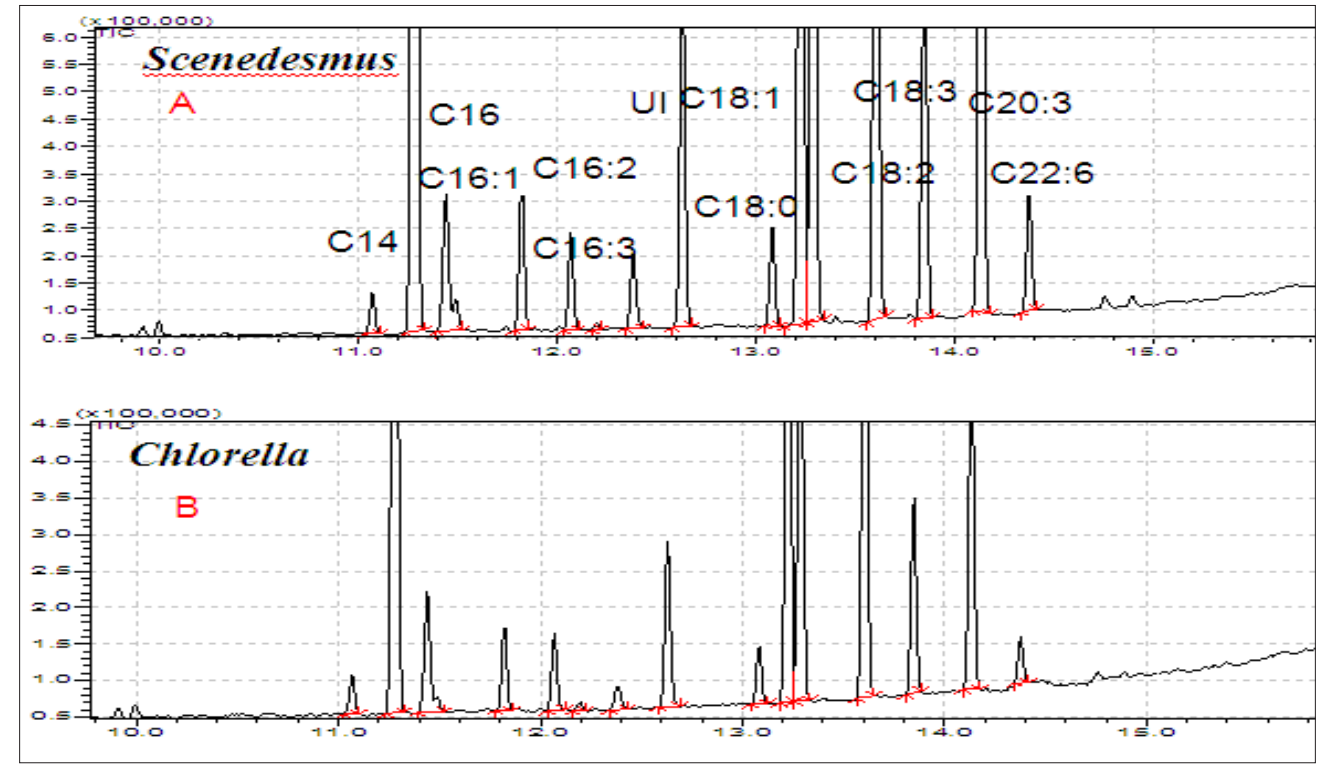

Figure 4: GC-MS (quadrupole, EI) profile of FAMEs of Algal oils (chloroform-methanol extracts) cultivated in WC-Superphosphate-Chilean saltpeter medium. 


\section{Monitoring of lipid extraction process and analyses of algal oils by FTIR}

FTIR techniques are extensively used for functional group analyses of algal oils such as hydroxyl, amides, phosphates, ester, free acids, longer alkyl chains, unsaturations etc. Based on functional groups information, the biochemical composition of glycerides, free fatty acids, amides (proteins), and glycero/glycol/ phospho components could be ascertained as explained in the detailed investigation of algal oils obtained from different types of microalgae and yeast oils $[13,42]$. The technique is particularly very useful in the monitoring of free fatty acid generated during cultivation of biomasses from different species under different nutrient media [8,9]. The application for the differentiation of fat (TG) and fatty acids (FA) has been demonstrated for algal oils obtained by ultrasonic extraction of biomasses of Scenedesmus sp. cultivated under diverse conditions as shown in the Figure 5.

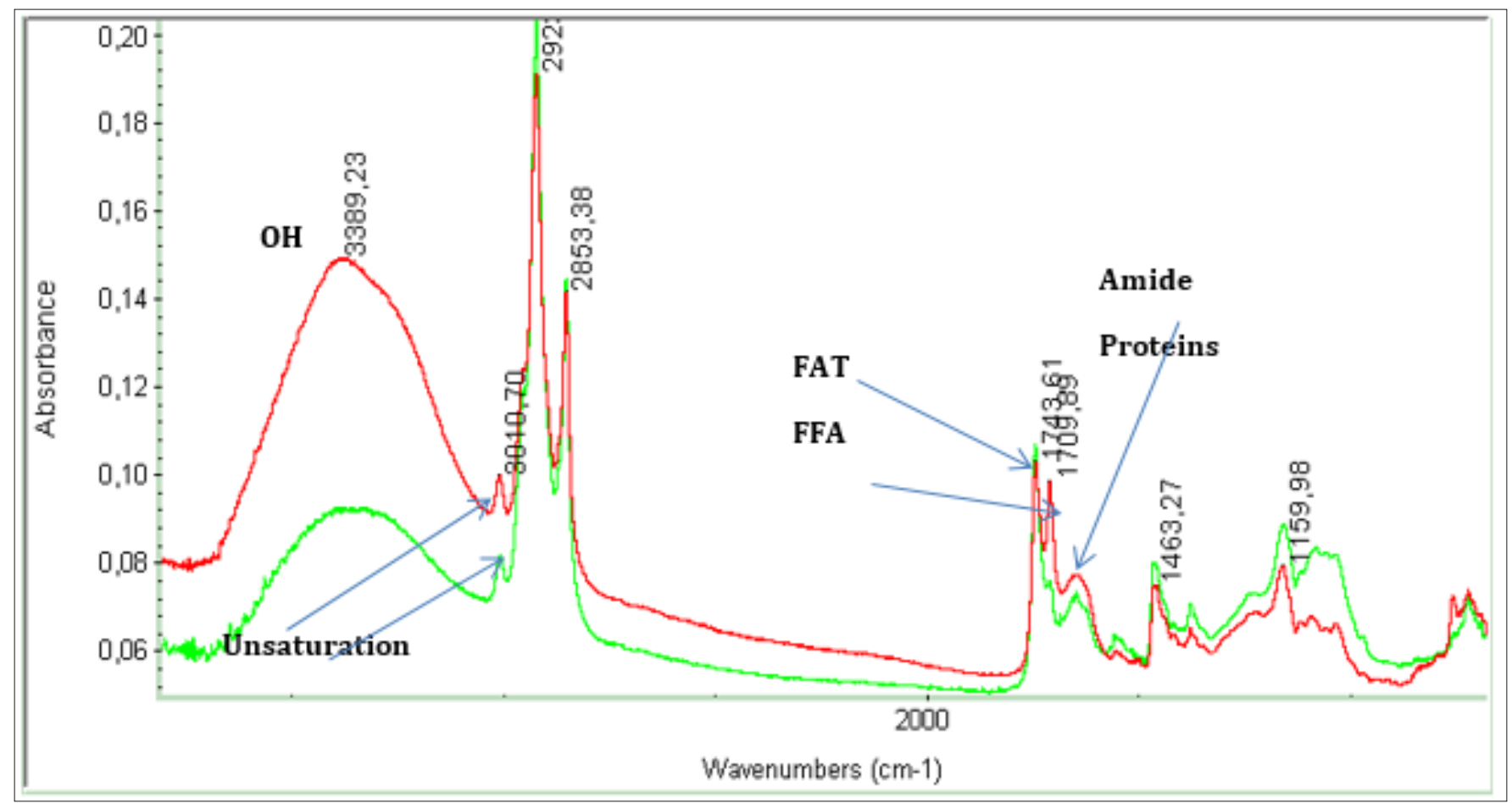

Figure 5: ATR-FTIR spectra of algal extract of Scenedesmus sp. cultivated under different nutrient media as marked red and green.

As discussed in the preceding section of extraction of lipids from algae biomass, various solvent of different polarity and their blends are used for extraction of algal oils. It is also essential to monitor the total extraction process including extraction efficiency of different solvent towards extraction of neutral and polar lipids. It has been demonstrated that polar solvents such as methanol have preference towards neutral and polar lipids comprising of polyunsaturated fatty acids such as C22:6 and C18:3 as revealed by combined NMR and GC-MS analyses [8,9]. FT-IR spectroscopy, particularly attenuated total reflectance (ATR), has proved to be an authentic technique for monitoring the extraction efficiency as well as functional group analyses correlated to biochemical composition of solid biomasses and algal oils for assessing the biodiesel and coproduct potential $[13,42,45]$. Hexane/cyclohexane is a preferred non polar solvent for extraction of neutral lipids (TG) due to its much higher efficiency towards neutral lipids at low cost $[8,9,44,46]$. The extraction efficiency of each solvent (cyclohexane, chloroform, methanol) toward extraction of neutral lipids (total glycerides (TG), free fatty acids (FFA), and polar lipids from the biomasses of Chlorella species have been determined and compared with regards to the nature of fatty acid components extracted in each solvent fractions as shown in the Figure 6 . The cyclohexane and chloroform have extracted the maximum amount of neutral lipids compared to methanol as indicated by the intensity of ester band at $1744 \mathrm{~cm}^{-1}$. The polar lipids including sugars/carbohydtrates and starch are extracted in higher amount in methanol compared to cyclohexane and chloroform as indicated by the bands intensity around $1000 \mathrm{~cm}^{-}$ ${ }^{1}(\mathrm{COC}, \mathrm{COH})$ and around $3450 \mathrm{~cm}^{-1}(\mathrm{OH})$. It is also evident from the spectral analyses that methanol extract is enriched with lipids comprising of higher amount of unsaturated fatty acids as indicated by intensity of the of the bands due to unsaturated functional group $(\mathrm{CH}=\mathrm{CH})$ at $2970 \mathrm{~cm}^{-1}$. The monitoring of extraction of lipids from biomasses is also carried out by ATR- FTIR as reported in case of yeast and algal extracts $[13,42]$. In the present study it has been demonstrated for a solid biomass obtained from Chlorella sp., extracted with chloroform-methanol blend as indicated in the ATRFTIR spectra of solid biomass (blue) and its residue (red)(Figure 7). The extraction efficiency towards lipids has been estimated to be $85 \%$ based on the area of the ester bands at $1744 \mathrm{~cm}^{-1}$ as explained in the reference [13]. 


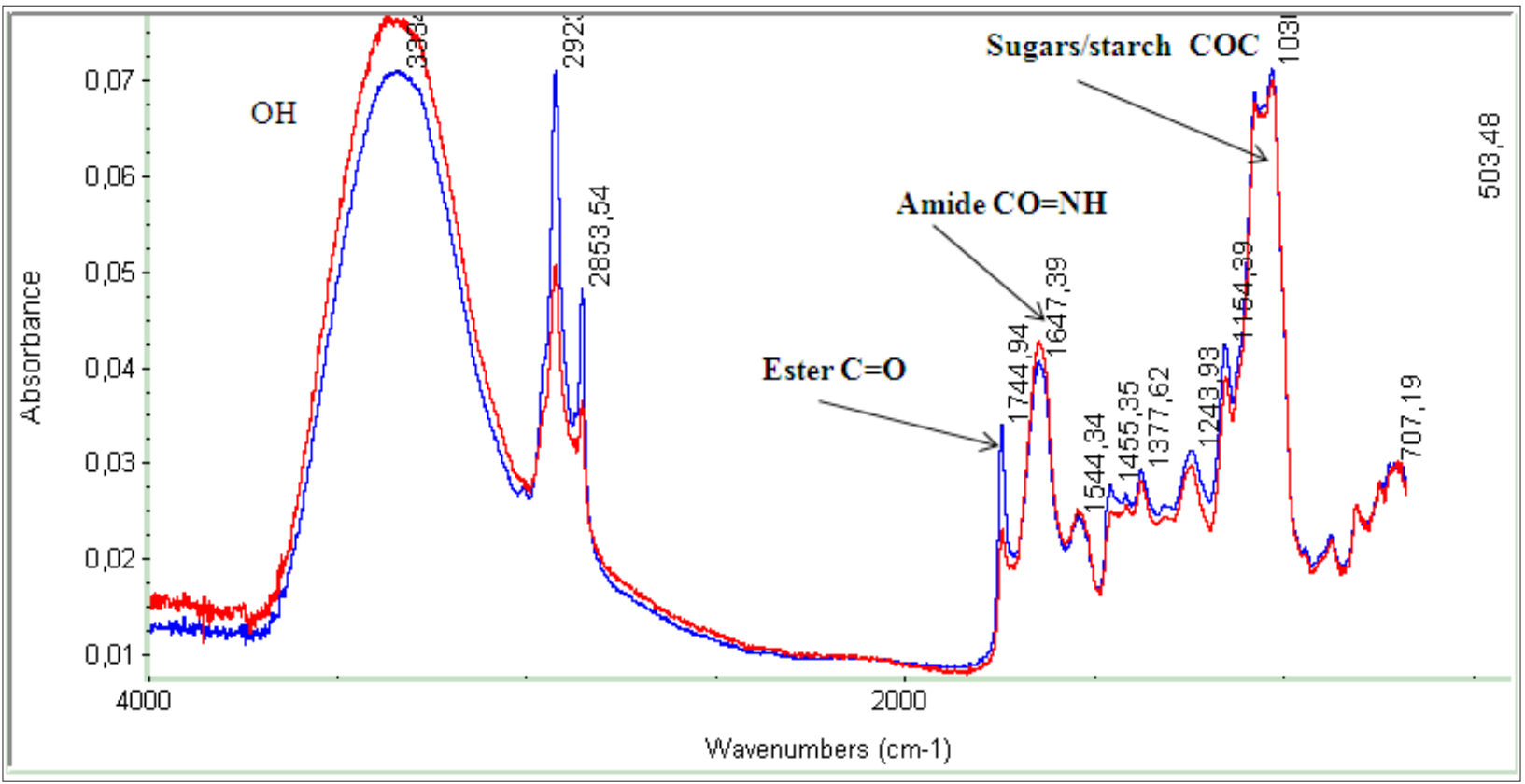

Figure 6: ATR-FTIR spectra of biomass of Chlorella sp. Blue=as such, red= residue after extraction in ChloroformMethanol blend.

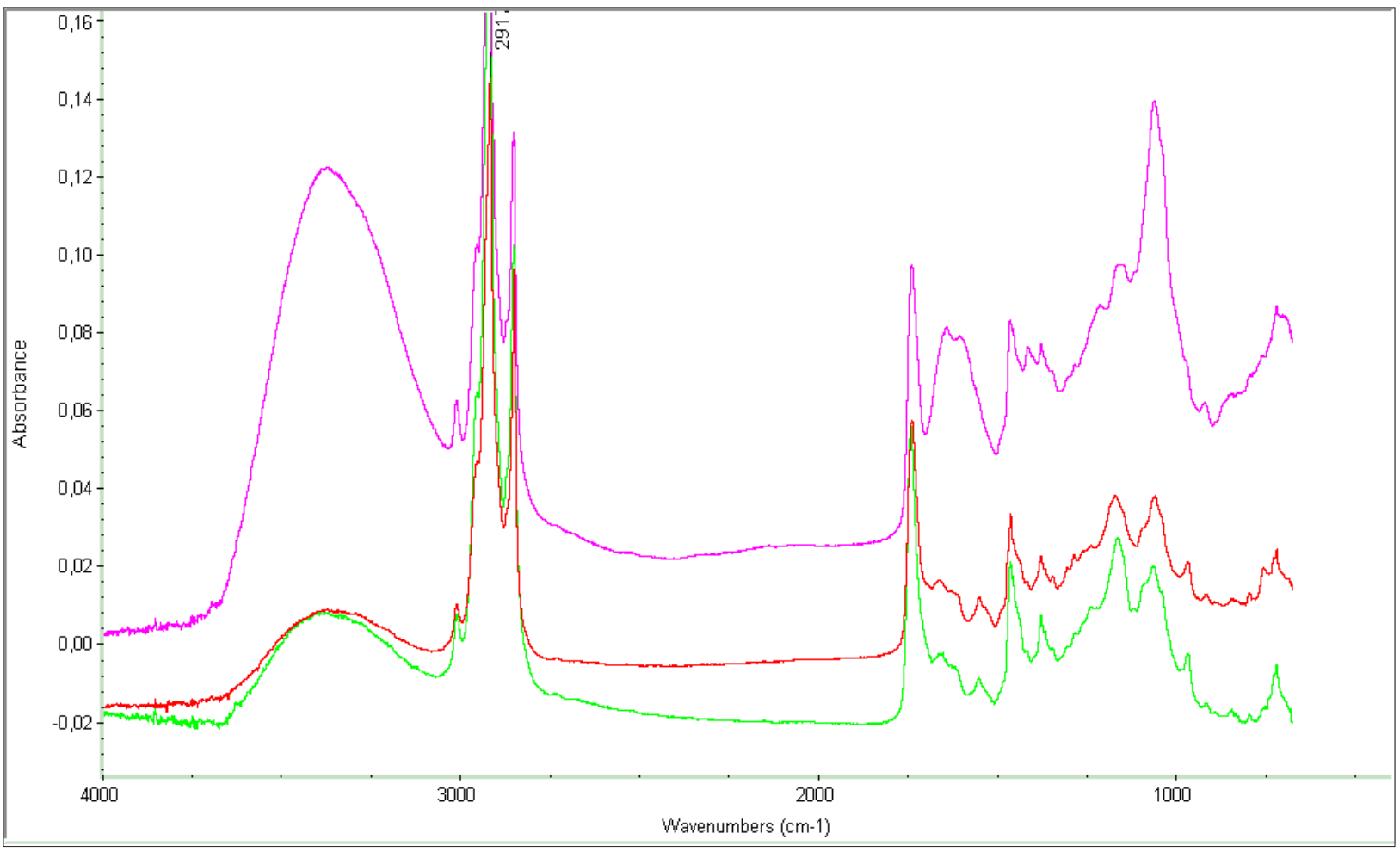

Figure 7: ATR-FTIR spectra of different solvent extracts of biomass of Chlorella sp.

\section{PUFA potential of microalgae}

Polyunsaturated fatty acids (n-3, omega3; PUFA), C18:3 (linolenic; ALA, GLA), C20:4 (arachidonic, ARA), C20:5 (EPA) and C22:6 (DHA), are important in tissue integrity and have beneficial health effects in curing inflammatory diseases, heart problems, arthritis, asthma, and headache. They may also protect against depression, dementia, cancer, and arthritis [2,49]. Since these are not produced by body, these are to be supplemented from natural sources such as fish, vegetable, plant and algal oils. The potential microalgae species, Senenedesmus, Cholrella, Porphyridium 
cruentum, Arthrospira platensis, Odontella, and I. galbana have been cultivated for their ability to synthesize these valuable fatty acids. Species like Phaeodactylum tricor-nutum, have shown enormous potentials for cultivation on a commercial scale. Eastern flower is the source of gama linolenic acid (GLA), which has unique power to cure chronic inflammation, eczema, dermatitis, asthma, cancer, diabetes etc [49]. The plant-based seeds, such as hemp, chia, walnut, flaxseeds, edamame and kidney beans are potential sources of ALA matching most of the Microalgae sp. The microalgae Spirulina sp. is the proven source of GLA and can be cultivated on commercial scale under controlled nutrients [10]. As revealed and discussed in the preceding sections of NMR, MS/GC-MS and FTIR analyses of algal oil that microalgae biomasses are rich sources of
PUFAs including essential DHA (C22:6) and GLA (gamma C18:3). It is important to monitor the cultivation process for the assessment of PUFAs potential. NMR techniques have been proved rapid and direct for determination of C18:3 and C22:6 [8-10] (Figures 1 \& 2). A correlation curve of PUFAs determined by 1 HNMR using the equation 4 and determined by GC-MS for large number of samples cultivated in fresh and waste water(WW) showed an excellent R2 $=0.983$ considering the diversity of the chemical composition of algal extracts (Figure 8). It also indicated that NMR was a choice of comparative technique for monitoring and determination of PUFAs content, particularly effect of nitrogen rich media on yield of PUFAs $[8,9]$, and during extraction of PUFAs by various processes [22$24,50,51]$.

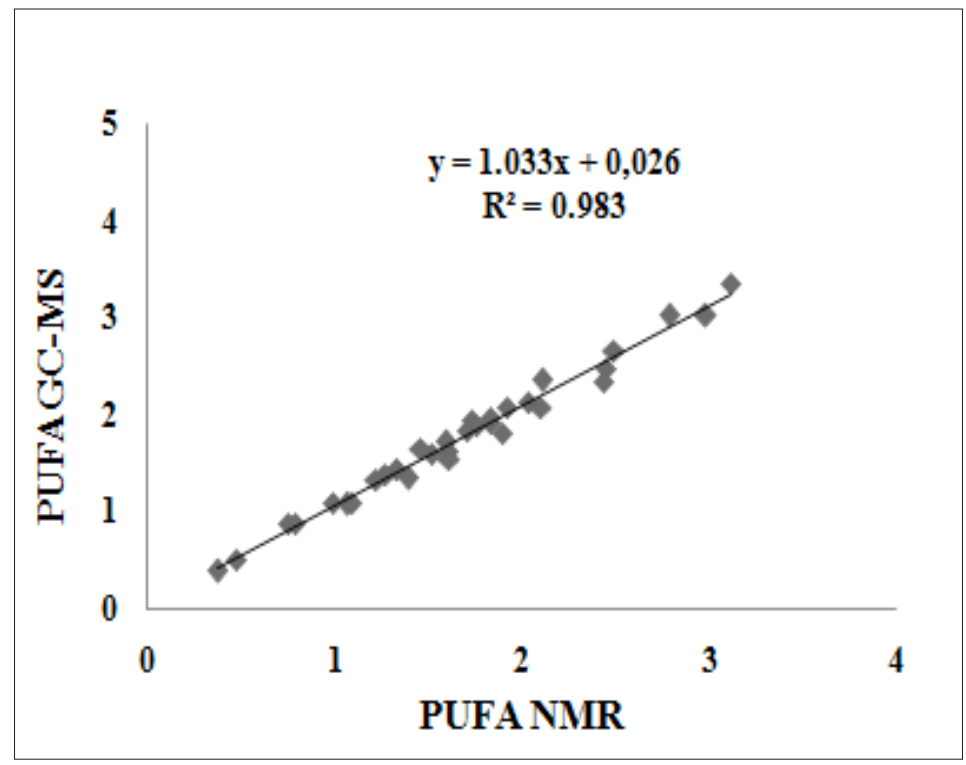

Figure 8: ATR-FTIR spectra of biomass of Chlorella sp. Blue=as such, red= residue after extraction in ChloroformMethanol blend.

\section{Commercial prospects of biodiesel}

Microalgae species are potential feedstocks for biodiesel production due to high lipids contents $50-80 \%$ of dry cell weight, and some species like B. braunii can accumulate up to $60 \%$ of oil in the biomass compared to 5-10\% oil content of agriculture oil crops. However, there are many cultivation, operational and maintenance problems such as harvesting, drying, oil extraction, and biodiesel conversion (transesterification) steps, which have been proved to be all energy intensive with high cost of initial investment, which make un-economical for the production of biodiesel and other co-products. In order to produce biodiesel with cost economics comparable to those of plant crops, the innovative research efforts have already been initiated in processes involving, 1) strain selection from oleaginous microalgae species with maximum lipid/ oil yield productivity, 2) biomass mass cultivation with improved management of nutrients, gas exchange, and seawater recycling, 3) low-energy harvesting \& dewatering, 4) extraction of lipids (TAG) process that should involves minimum use of solvents/ co-solvents including efficient recovery after extraction, 5) coproduct development with high nutritional and commercial value of non-fuel products and 6) integrated design techno-economic and life cycle assessment of a fully integrated technology pathway. Metabolic engineering approaches using techniques of molecular biology and genetic engineering are the innovative pathways being used to increase lipid accumulation in microalgae biomass and ultimately yield of biodiesel production [1-4]. Determining strains of algae that are highly productive could help lower the cost of biofuel production. These efforts will definitely would yield results best suited for the laboratory to industrial scale exploitation [1,2,51-53].

There are few breakthrough reports on the cost-effective extraction process published recently in a book titled "Oilgae Comprehensive reports". In order to produce a biodiesel with cost equivalent to conventional diesel, Origin Oil Company has developed an innovative process called quantum fracturing, which is a single step cost effective oil extraction process. It's a low-cost oil extraction innovative process that provides energy efficient and continuous production by the use of Helix bioreactor and quantum fracturing technology employing electromagnetic waves for efficient cell disruption. The oil is extracted in a single step oil extraction; 
separate oil, water and biomass in a single step in contrast to usual processes that involve separate processes of water separation, decoagulations, drying, extraction etc. Cavitation Technologies Inc. (CTI) has developed a technology that is able to extract oil from algae on a continuous basis utilizing cavitation based extraction system. It employs nano reactor to create cavitation bubbles in a solvent material. When these bubbles collapse near the cell walls it creates shock waves and liquid jets that cause those cells walls to break and release their contents into the solvent. Microalgal biodiesel is produced in a biorefinery based production strategy, where each and every component of the biomass can be used to produce valuable products such as. polyunsaturated fatty acids (gammalinolenic, arachidonic, eicosapentaenoic, docosahexaenoic) ,vitamins, carotenoids (astaxanthin, beta-carotene, etc.) etc. Thus, cost of biodiesel will be supplemented by the commercial production of these valuable by-products [1-4,10,48-53]. The company involved in the commercial production of biodiesel and co products as collected from source ETIP Bioenergy, are Muradel "algae-crude" demonstration, Australia; Sapphire Energy Green "Crude Farm; Solazyme demonstration of commercial production of biofuels and biochemicals using heterotrophic algae; Cellana and Neste Oil agreement for commercial-scale algae production; Algae. Tec Ltd Australia; BioProcess Algae LLC; and Algenol.

\section{Conclusion}

Thus, it is quite evident that biomasses cultivated by microalgae has a viable and useful commercial product potential which finds extensive application in energy (biodiesel), neutraceuticals, functional foods (PUFAs, carotenoids), nanomaterials etc. industry. The composition of the algal oils extracted is dependent upon the types of microalgae species used and nutrient media employed for the cultivation of a biomass. In every step from strain selection to the final product, a planned analytical strategy involving rapid and direct methodologies would be required to analyze biomasses for enhanced triglycerides and co-product (PUFA etc.) potential, particularly at stages of selection of strains and extraction of lipids. As demonstrated in the preceding section, the single $1 \mathrm{H}$ NMR spectral analyses of a solvent extracts would provide complete analyses with ease, directness and rapidness with regards to the composition and quality aspects of the biomasses such as lipid \& TG content, and fatty acid profile including PUFA content. Combining NMR with MS/GC-MS and FTIR as a viable analytical strategy will provide complete biochemical composition of algal oil for the assessment of biodiesel and product potential as well as monitoring the cultivation process for lipid yield enhancement. This will also add to the reduction of cost of production and saving of time for total monitoring process [8-10,46-48,50,52,53]. In order to have a profitable cost economics of the production of biodiesel, the extraction of the co-products may be integrated with bio-refinery process [54].

\section{References}

1. Mata TM, Martins AA, Caetano NS (2010) Microalgae for biodiesel production and other applications: a review. Renew Sust Energy Rev 14(1): 217-232.
2. Khan MI, Shin JH, Kim JD (2018) The promising future of microalgae: current status, challenges, and optimization of a sustainable and renewable industry for biofuels, feed, and other products. Microb Cell Fact 17(1): 36.

3. Garlapati VK, Gour RS, Sharma V (2017) Current status of biodiesel production from microalgae in India.

4. Mallick N, Bagchi SK, Koley S, Singh AK (2016) Progress and challenges in microalgal biodiesel production. Front Microbiol 7: 1019.

5. Contreras-Angulo JR, Mata M, Cuellar-Bermudez SP, Caetano NS, Chandra RJ, et al. (2019) Symbiotic co-culture of Scenedesmus sp. and Azospirillum brasilense on $\mathrm{N}$-deficient media with biomass production for biofuels. Sustainability 11(3): 707.

6. Indonesia H, Widayatand, Kumoro AC (2012) Potency of microalgae as biodiesel source. Int Journal of Renewable Energy Development 1(1): 23-27.

7. Raymond ES, Kadiri MO (2017) Decolourization of textile dye using microalgae (Chlorella vulgaris and Sphaerocystis schroeteri). IJIRAS $4(9): 15-20$

8. Sarpal AS, Teixeira CMLL, Silva PRM, Lima GM, Silva SR, et al. (2015) Determination of lipid content of oleaginous microalgae biomass by NMR spectroscopic and GC-MS techniques. Anal Bioanal Chem 407(13): 3799-3816.

9. Sarpal AS, Teixeira CMLL, Silva PRM, Monteiro TV, Itacolomy J, et al. (2015) NMR techniques for determination of lipid content in microalgal biomass and their use in monitoring the cultivation with biodiesel potential. Appl Microbiol Biotechnol 100(5): 2471-2485.

10. Sarpal AS, Costa ICR, Teixeira CMLL, Filocomo D, Candido R, et al. (2016) Investigation of biodiesel potential of biomasses of microalgaes chlorella, spirulina and tetraselmis by NMR and GC-MS techniques. J Biotechnol Biomater 6: 220.

11. Winwood RJ (2013) Recent developments in the commercial production of DHA and EPA rich oils from micro-algae. OCL 20(6): D604.

12. Chauton MS, Reitan KI, Norsker NH, Kleivdal H (2015) A technoeconomic analysis of industrial production of marine microalgae as a source of EPA and DHA-rich raw material for aquafeed: Research challenges and possibilities. Aquaculture 436: 95-103.

13. Sarpal AS, Silva PRM, Pinto RF, Cunha VS, Daroda RJ, et al. (2014) Biodiesel potential of oleaginous yeast biomass by NMR spectroscopic techniques. Energy Fuels 28(6): 3766-3777.

14. Sarpal AS, Silva PRM, Silva SR, Monteiro TV, Itacolomy J, et al. (2015) A direct method for the determination of iodine value of biodiesel by quantitative nuclear magnetic resonance (q1H-NMR) spectroscopy. Energy Fuels 29(12): 7956-7968.

15. Kumar R, Bansal V, Patel MB, Sarpal AS (2014) Compositional analysis of algal biomass in a nuclear magnetic resonance (NMR) tube. Journal of Algal Biomass Utilization 5: 36-45.

16. Sarpal AS, Teixeira CMLL, Mesquita S, Costa ICR, Silva PRM (2018) Biodiesel and product potential of microalgae Dunaliella salina by NMR Techniques. Adv Biotech \& Micro 11(3): 555812.

17. Sarpal AS, Silva PRM, Monteiro TV, Fonseca M, Cunha VS, et al. (2016) Monitoring of development of certified reference material of biodiesel by high field NMR spectroscopic techniques. Journal of Scientific and Industrial Metrology 1(3): 1-26.

18. Takisawa K, Kanemoto K, Kartikawati M, Kitamura Y (2014) Overview of biodiesel production from microalga. Agriculture 9(2): 120-128.

19. Aden A, Coleman AM, Pienkos PT, Skaggs RJ, Venteris ER, et al. (2012) Renewable diesel from algal lipids: An integrated baseline for cost, emissions, and resource potential from a harmonized model. Technical Report ANL/ESD/12-4 NREL/TP-5100-55431 PNNL-21437. 
20. Bishop WM, Zubeck HM (2012) Evaluation of microalgae for use as nutraceuticals and nutritional supplements. J Nutr Food Sci 2: 147.

21. Portela NA, Oliveira ECS, Neto AC, Rodrigues RRT, Silva SRC, et al. (2016) Quantification of biodiesel in petroleum diesel by $1 \mathrm{H}$ NMR: Evaluation of univariate and multivariate approaches. Fuel 166: 12-18.

22. Raheem A, Prinsen P, Vuppaladadiyam AK, Zhao M, Luque R (2018) A review on sustainable microalgae based biofuel and bioenergy production: Recent developments. J Cleaner Production 181: 42-59.

23. Zhang Y, Ward V, Dennis D, Plechkova NV, Armenta R, et al. (2018) Efficient extraction of a docosahexaenoic acid (DHA)-rich lipid fraction from Thraustochytrium sp. using ionic liquids. Materials 11(10): E1986.

24. Oviyaasri M, Manjuladevi M, Anitha R, Narmatha M, Kavitha J (2017) Extraction and isolation of polyunsaturated fatty acids from microalgae Tetraselmis Sp. IJIRSET 6(3): 4810-4813.

25. Di Sanzo G, Mehariya S, Martino M, Larocca V, Casella P, et al. (2018) Supercritical carbon dioxide extraction of astaxanthin, lutein, and fatty acids from Haematococcus pluvialis microalgae. Mar Drugs 16(9): 334.

26. DeMorais MG, da Silva VB, de Morais EG, Costa JAV (2014) Biological effects of Spirulina (Arthrospira) Biopolymers and biomass in the development of nanostructured scaffolds. BioMed Research International 2014: 1-9.

27. Hafez EE, Kabeil SS (2013) Antimicrobial activity of nano-silver particles produced by micro algae. Journal of Pure and Applied Microbiology 7: 35-42.

28. Rezanka T, Lukavsky J, Nedbalová L, Sigler K (2011) Effect of nitrogen and phosphorus starvation on the polyunsaturated triacylglycerol composition, including positional isomer distribution, in the alga Trachydiscus minutus. Phytochemistry 72(18): 2342-2351.

29. Al-Qasmi M, Raut N, Talebi S, Al-Rajhi, Al-Barwani T (2012) A review of effect of light on microalgae growth. Proceedings of the World Congress on Engineering 1: 1-3.

30. Islam MA, Magnusson M, Brown RJ, Ayoko GA, Nabi MN, et al. (2013) Microalgal species selection for biodiesel production based on fuel properties derived from fatty acid profiles. Energies 6(11): 5676-5702.

31. Brennan L, Owende P (2010) Biofuels from microalgae- a review of technologies for production, processing, and extractions of biofuels and co-products. Renew Sustain Energy Rev 14(2): 557-577.

32. https://www.intechopen.com/books/biofuels-status-and-perspective/ microalgal-biofuel

33. Silva C, Soliman E, Cameron G, Fabiano LA, Seide WD, et al. ( 2014) Commercial-scale biodiesel production from algae. Ind Eng Chem Res 53(13): 5311-5324.

34. Li Y, Naghdi FG, Garg S, Adarme-Vega TC, Thurecht KJ, et al. (2014) A comparative study: the impact of different lipid extraction methods on current microalgal lipid research. Microbial Cell Factories 13: 14.

35. Meng X, Yang J, Xu X, Zhang L, Nie Q (2009) Biodiesel production from oleaginous microorganisms-Review. Renewable Energy 34(1): 1-5.

36. Halim R, Danquah MK, Webley PA (2012) Extraction of oil from microalgae for biodiesel production: A review Biotechnology Advances 30(3): 709-732.

37. Enamala MK, Enamala S, Chavali M, Donepudi J, Yadavalli R, et al. (2018) Production of biofuels from microalgae - A review on cultivation, harvesting, lipid extraction, and numerous applications of microalgae. Renewable and Sustainable Energy Reviews 94: 49-68.
38. Yao L, Gerde JA, Show L, Tong W, Harrata KA (2015) Microalgae lipid characterization. J Agric Food Chem 63(6): 1773-1787.

39. Nyuk-Ling M, Ahmad A, Kit-Yinn T, Su-Shiung L, Thye-San C (2018) Metabolites re-programming and physiological changes induced in Scenedesmus regularis under nitrate treatment. Scientific Reports 8: 9746.

40. Gao C, Xiong W, Zhang Y, Yuan W, Wu Q (2008) Rapid quantitation of lipid in microalgae by time-domain nuclear magnetic resonance. J Microbiol Methods 75(3): 437-440.

41. Chopra A, Singh D, Kumar R, Sugmaran V, Sarpal AS (2011) Determination of Polyunsaturated Fatty Esters (PUFE) in biodiesel by GC/GC-MS and NMR techniques. J Am Oil Chem Soc 88: 1285-1296.

42. Sarpal AS, Sharma BK, Scott J, Kumar R, Sugmaran V, et al. (2016) Compositional analyses of oil extracts of microalgae biomasses by NMR and chromatographic techniques. Anal Bioanal Sep Tech 1(1): 17-41.

43. Laurens LML, Dempster TA, Jones HDT, Wolfrum EJ, Van Wychen S, et al. ( 2012) Algal biomass constituent analysis: Method uncertainties and investigation of the underlying measuring chemistries. Anal Chem 84(4): 1879-1887.

44. Ferreira AF, Dias APS, Carla SD M, Silva CM, Costa M (2016) Effect of low frequency ultrasound on microalgae solvent extraction: Analysis of products, energy consumption and emissions. Algal research 14: 9-16.

45. Orfang K, Zimmermann B, Kosa G, Kohler A, Shapaval V (2017) FTIR Spectroscopy for evaluation and monitoring of lipid extraction efficiency for oleaginous fungi. PLoS One 12(1): e0170611.

46. Hee-Yong S, Sang-Hyeok S, Young-Jin R, Ji-Hyun Y, Sang-Min L, Choul-Gyun L (2018) Lipid extraction from Tetraselmis sp. microalgae for biodiesel production using hexane-based solvent mixtures. Biotechnology and Bioprocess Engineering 23: 16-22.

47. Nuzzo G, Gallo C, dlppolito G, Cutignano A, Sardo A, et al. (2013) Composition and quantitation of microalgal lipids by ERETIC 1H NMR method. Mar Drugs 11(10): 3742-3753.

48. Danielewicz MA, Anderson LA, Franz AK (2011) Triacylglycerol profiling of marine microalgae by mass spectrometry. Journal of Lipid Research 52(11): 2101-2108.

49. Caporgno MP, Mathys A (2018) Trends in microalgae incorporation into innovative food products with potential health benefits. Front Nutr 5 : 58.

50. Singh G, Patidar SK (2018) Microalgae harvesting techniques: A review. J Environ Manage 217: 499-508.

51. Kumar J, Garlapati VK, Dash A, Scholz P, Banerjee R (2017) Sustainable green solvents and techniques for lipid extraction from microalgae: A review. Algal Research 21: 138-147.

52. Silva R, Stephen C (2014) Commercial-scale conversion of algae to biofuel. Publicly Accessible Penn Dissertations.

53. Sivagnana PKK, Vadivel M, Arvindnarayan S, Kumar G (2019) Biodiesel potentiality of microalgae species: evaluation using various nitrogen sources. Waste and Biomass Valorisation, pp. 1-9.

54. Chew KW, Yap JY, Show PL, Suan NH (2017) Microalgae biorefinery: High value products perspectives. Bioresource Technology 229: 53-62. 